\title{
How to assess the value of medicines?
}

\author{
Steven Simoens* \\ Research Centre for Pharmaceutical Care and Pharmaco-economics, Katholieke Universiteit Leuven, Leuven, Belgium
}

Edited by:

Brian Godman, Karolinska Institutet Sweden

\section{Reviewed by:}

Brian Godman, Karolinska Institutet Sweden

Lars L. Gustafsson, Karolinska

Institutet, Sweden

F. Cankat Tulunay, Ankara Üniversitesi

Tıp Fakültesi, Turkey

\section{*Correspondence}

Steven Simoens, Research Centre for

Pharmaceutical Care and Pharmaco-

economics, Katholieke Universiteit

Leuven, Onderwijs en Navorsing 2,

Herestraat 49, P.O. Box 521, 3000

Leuven, Belgium.

e-mail: steven.simoens@pharm.

kuleuven.be
This study aims to discuss approaches to assessing the value of medicines. Economic evaluation assesses value by means of the incremental cost-effectiveness ratio (ICER). Health is maximized by selecting medicines with increasing ICERs until the budget is exhausted. The budget size determines the value of the threshold ICER and vice versa. Alternatively, the threshold value can be inferred from pricing/reimbursement decisions, although such values vary between countries. Threshold values derived from the value-of-life literature depend on the technique used. The World Health Organization has proposed a threshold value tied to the national GDP. As decision makers may wish to consider multiple criteria, variable threshold values and weighted ICERs have been suggested. Other approaches (i.e., replacement approach, program budgeting and marginal analysis) have focused on improving resource allocation, rather than maximizing health subject to a budget constraint. Alternatively, the generalized optimization framework and multi-criteria decision analysis make it possible to consider other criteria in addition to value.

Keywords: economic evaluation, value, incremental cost-effectiveness ratio, threshold

\section{INTRODUCTION}

Economic evaluation serves as a tool to assess the value of a medicine by comparing the costs and outcomes of a medicine with those of a relevant comparator (Drummond et al., 2005). The results of an economic evaluation can be expressed in the form of an incremental cost-effectiveness ratio (ICER). This ratio relates the difference in costs between a medicine and the comparator to the difference in outcomes. Evidence derived from economic evaluations is used to inform pharmaceutical pricing/reimbursement decisions in many countries.

The aim of this study is to discuss current advances and future directions for assessing the value of medicines. Firstly, this study outlines the methodological basis for assessing the value of medicines in comparison with a threshold ICER, reviews the strengths and weaknesses of the threshold ICER approach, and discusses various approaches to determine the threshold ICER. Secondly, a number of alternative approaches to assessing the value of medicines are presented. This information will aid health care decision makers and researchers to interpret economic evaluations and their results for the purpose of decision making.

\section{MATERIALS AND METHODS}

It was not appropriate to conduct a systematic literature review of how an economic evaluation assesses the value of medicines. This is because a conventional search strategy using terms such as "economic evaluation," "value," "efficiency" and "costeffectiveness" is likely to result in a very large number of irrelevant references. Instead, the so-called "citation pearl growing" method was adopted. This method identified an initial set of core references on economic evaluation and assessment of the value of medicines. A first search wave then looked for papers that cite the set of core references. Successive waves were carried out to identify papers that refer to the papers that have been selected in a previous wave. This process continued until no additional papers were included.

Papers were identified by searching PubMed, specific health economicjournals (Cost-Effectiveness and ResourceAllocation, European Journal of Health Economics, Expert Review of Pharmacoeconomics and Outcomes Research, Health Economics, Health Technology Assessment, International Journal of Technology Assessment in Health Care, Journal of Health Economics, Journal of Medical Economics, Medical Decision Making, PharmacoEconomics, Value in Health), and the bibliography of included papers. The search was limited to English-language papers published in 2010 or earlier.

The results of the literature search are presented in Figure 1.

\section{METHODOLOGICAL BASIS OF THE ICER}

This section outlines the basic principles underlying the threshold ICER approach and its variant, the net health benefit approach.

\section{THE THRESHOLD ICER APPROACH}

The use of the ICER in informing decisions to maximize health subject to a budget constraint was originally proposed by Weinstein and Zeckhauser (1973). These authors considered the case of a health care payer who could fund some, but not all medicines due to a budget constraint. It can be shown that, if medicines are ranked from the lowest to the highest ICER (a so-called league table), health can be maximized by selecting medicines with increasing ICERs until the budget is exhausted. The ICER of the last medicine (i.e., the medicine with the highest cost per unit of outcome ratio) to be selected is called the threshold ICER or lambda $(\lambda)$.

The threshold ICER, $\lambda$, represents the opportunity cost of resources at the margin. If a decision maker considers reimbursing a new medicine from the same budget, the ICER of the new 


\begin{tabular}{|c|c|c|}
\hline Search waves & Topic & Number of citations \\
\hline Core references & Threshold ICER approach & 10 citations identified \\
\hline First wave & $\begin{array}{l}\text { Approaches to determine } \\
\text { threshold ICER }\end{array}$ & 24 citations identified \\
\hline Second wave & $\begin{array}{l}\text { Alternative approaches to } \\
\text { assess medicine value }\end{array}$ & 5 citations identified \\
\hline Third wave & Additional references & 10 citations identified \\
\hline
\end{tabular}

medicine needs to be compared with the threshold ICER of the last medicine that is currently reimbursed. If the ICER of the new medicine is lower than $\lambda$, the replacement of the last medicine that is currently reimbursed by the new medicine would increase total health subject to the budget constraint. If the ICER of the new medicine exceeds $\lambda$, reimbursement of the new medicine would reduce total health.

For decision-making purposes, the threshold ICER represents the maximum cost per unit of outcome that a health care payer is willing to pay for a medicine. This means that a medicine with an ICER below the threshold value $\lambda$ is likely to be accepted for reimbursement by a health care payer and a medicine with a ratio exceeding the threshold is likely to be refused.

This methodology draws on several assumptions, including the existence of a fixed budget, the use of health maximization as the only criterion informing resource allocation decisions, the availability of complete information on costs and outcomes of all medicines and comparators in the league table, perfect divisibility and constant returns to scale of medicines. A fixed budget means that the size of the budget does not change within a specific time period. Perfect divisibility means that a health care payer can fund medicines in infinitely small units (thus avoiding the problem of indivisibilities). Constant returns to scale apply if the ICER does not depend on the volume of medicines.

Under this model, the size of the budget determines the value of the threshold ICER. If the budget increases, medicines with higher ICERs can be selected. If the budget decreases, only the medicines with the highest value (i.e., the lowest ICERs) can be selected. Alternatively, the specification of a value for $\lambda$ determines the size of the budget to be spent on medicines. If a health care payer sets a threshold value for $\lambda$, this implies that the payer is willing to select all medicines with an ICER below $\lambda$ (because they are deemed to provide value), thereby setting the size of the budget.

It should be noted that the threshold ICER is subject to uncertainty. As there is uncertainty in economic evaluation related to, for instance, methodological disagreements, researchers' assumptions, imprecise data, need to extrapolate results over time, need to generalize results to other settings or other countries, the ICER of a medicine is not set, but stochastic (Sendi et al., 2002). Furthermore, new medicines constantly enter the market and old medicines are withdrawn from the market by pharmaceutical companies or are delisted (e.g., in France). This implies that the medicines listed in a league table change over time, thus resulting in a new value for $\lambda$.

The threshold ICER depends on health care productivity. If the productivity in the health care sector increases through, for example, substitution of generic medicines for originator medicines, a greater health improvement can be gained from the same budget. This implies that, if the size of the budget remains constant, then the threshold ICER will decrease.

\section{NET HEALTH BENEFIT}

The net health benefit approach uses a threshold ICER to generate a net health benefit measure expressed in monetary terms (Stinnett and Mullahy, 1998). In essence, the additional costs of a medicine vis-à-vis the comparator are divided by the threshold ICER to generate the following term:

$\left(\mathrm{C}_{1}-\mathrm{C}_{0}\right) / \lambda$

where $C_{1}$ is the cost of a medicine; $C_{0}$ is the cost of the comparator; $\lambda$ is the threshold ICER.

This term represents the additional outcomes that the medicine would be expected to generate if it had an ICER equal to the threshold ICER.

The net health benefit is defined as:

$\mathrm{NHB}=\left(E_{1}-E_{0}\right)-\left(C_{1}-C_{0}\right) / \lambda$

where $C_{1}$ is the cost of a medicine; $C_{0}$ is the cost of the comparator; $E_{1}$ and $E_{0}$ are the outcomes of a medicine and the comparator, respectively; NHB is the net health benefit; $\lambda$ is the threshold ICER.

A medicine provides value if the actual additional outcomes produced by the medicine exceed the additional outcomes that the medicine would be expected to generate if it had an ICER equal to the threshold ICER. In other words, a medicine provides value if the net health benefit is positive.

Given that the net health benefit approach reformulates the ICER into a net health benefit measure, the strengths and weaknesses of assessing the value of medicines by means of the ICER also apply to the net health benefit approach (cfr. infra). 


\section{STRENGTHS AND WEAKNESSES OF THE THRESHOLD ICER APPROACH}

The literature has identified a number of strengths and weaknesses of the threshold ICER approach that relates to its methodology or its use in decision making (see Table 1) (Eichler et al., 2004; Dolan et al., 2005; Donaldson and Gerard, 2005; Bell et al., 2006; Birch and Gafni, 2006b; Gafni and Birch, 2006; Cohen et al., 2007; Wettermark et al., 2008; Tilson and Barry, 2010).

The threshold ICER approach does not consider the budget impact of adopting a new medicine. This can be illustrated with the example of trastuzumab for early-stage breast cancer. Although trastuzumab is seen as beneficial in terms of the cost per QALY in many countries, it is associated with an appreciable increase in costs versus the product(s) it replaces. As a result, some patients may be denied treatment if a program involving trastuzumab is nationally adopted without any changes in budget allocation (Barrett et al., 2006). This funding issue may cause problems for regional health care payers with budget responsibility, leading to limited use of health economic data in practice by such payers (Godman et al., 2009).

Finally, it should be noted that in practice a limited number of new medicines have added health benefit, whereas the majority of medicines have a similar effectiveness to current alternatives. It is estimated that among those medicines with a health benefit, most new medicines have a health benefit only and approximately $10 \%$ of new medicines are truly innovative or have a significant added health benefit (Sermet et al., 2010). Consequently, calculating ICERs could only be relevant in reality for a minority of new medicines, with payers increasingly expecting similar or lower prices to current alternatives when new medicines are similar and expecting marginally increased prices when new medicines have an added benefit but are not innovative.

Table 1 | Strengths and weaknesses of the threshold ICER approach.

\section{(A) Strengths}

\section{METHODOLOGY}

+ Explicit methodology for informing resource allocation decisions.

\section{DECISION MAKING}

+ Increased consistency and transparency of decision-making process.

+ Enhanced public trust in resource allocation decisions.

+ Absence of a threshold ICER approach generates room for arbitrariness and ad hoc resource allocation decisions.

\section{(B) Weaknesses}

\section{METHODOLOGY}

- Setting a threshold value for $\lambda$ (implying that the payer funds all medicines with an ICER below $\lambda$ ) may lead to uncontrolled growth in pharmaceutical expenditure. Also, as the budget needed to fund additional medicines that satisfy the threshold ICER may originate from disinvestment of existing medicines (and their associated health outcomes), the net impact may be a reduction in total health.

- Decision makers focus on specific budget and do not consider costs outside the budget (so-called budget silo mentality).

- Complete information on costs and outcomes of all medicines and comparators in the league table is not available.

- Relevant information is not available (e.g., evidence on absolute rather than relative effectiveness, use of surrogate rather than final effectiveness measures)

- Perfect divisibility does not apply if decision makers wish to provide a medicine to all patients even if the ICER differs among various patient subgroups.

- Constant returns to scale do not apply because although the medicine volume is unlikely to affect effectiveness, it is likely to impact costs and, thus, the ICER.

- Problems associated with league tables include internal consistency of reported ICERs and transferability of ICERs between decision-making contexts.

\section{DECISION MAKING}

- Determination of explicit threshold ICERs is a politically sensitive issue.

- Companies may "play the system" by setting prices just under the threshold ICER value, which may mean higher prices in reality.

- The threshold value needs to rise with inflation, requiring constant adjustment.

- Decision makers consider other criteria in addition to value (e.g., equity, affordability, innovative nature of medicine, availability of alternative treatment options).

- Different threshold ICER values between countries leads to inequality between individuals depending on country of residence.

- Decision makers may not apply a single threshold ICER to different types of medicines and decision contexts.

- Difficulties involved in taking a decision taking into account uncertainty associated with cost-effectiveness results.

- Individuals may have a different threshold ICER depending on, for example, the amount, duration and type of outcome.

- Decision makers may find it difficult to discontinue paying for the last medicine that is currently reimbursed by the budget in the advent of a new medicine that provides better value.

- Factors such as whether decisions are legally binding or not influence medicine acceptance/rejection rates.

- Commercially-funded economic evaluations may be more likely to meet threshold ICER values, thus pointing to possible biases in study conduct. 


\section{ALTERNATIVE APPROACHES TO DETERMINE A THRESHOLD ICER}

Due to the lack of information on costs and outcomes of all medicines and comparators in the league table, it is in practice not possible to determine the value of the threshold ICER. Therefore, alternative approaches to determine the threshold ICER have been proposed.

\section{THRESHOLD ICERS DERIVED FROM MEDICINE PRICING/ REIMBURSEMENT DECISIONS}

Threshold ICERs can be derived from medicine pricing/reimbursement decisions. These threshold ICERs have either been explicitly specified by the health care payer or can be implicitly determined from examining past medicine pricing/reimbursement decisions. Table 2 provides an overview of threshold values used to inform pricing/reimbursement decisions in Australia (George et al., 2001), Canada (Laupacis et al., 1992), England and Wales (Rawlins and Culyer, 2004; Raftery, 2006), the Netherlands (Health Care Insurance Board, 1999), New Zealand (PHARMAC, 2007), Scotland (Webb, 2009), and the United States (Grosse, 2008). This Table shows that threshold values vary substantially between countries.

A retrospective analysis examined 355 medicines considered by the Australian Pharmaceutical Benefits Advisory Committee for reimbursement between 1991 and 1996 (George et al., 2001). Decisions to (not) reimburse medicines were investigated with a view to eliciting the threshold ICER that the committee applies to inform decisions. The study did not find a specific threshold ICER beyond which the committee is unwilling to reimburse a medicine. Rather, the authors observed that the committee was unlikely to reject a medicine for which the ICER is less than AUS $\$ 42,000$ per life year. Also, the committee was unlikely to recommend a medicine for which the ICER surpassed AUS\$76,000 per life year.

Table $\mathbf{2}$ |Threshold ICER values in a selection of countries.

\begin{tabular}{|c|c|c|}
\hline Country & $\begin{array}{l}\text { Threshold value } \\
\text { in local currency }\end{array}$ & $\begin{array}{l}\text { Threshold value } \\
\text { in Euro }\end{array}$ \\
\hline Australia & $\begin{array}{l}\text { AUS\$42,000-76,000 } \\
\text { per life year }\end{array}$ & $\begin{array}{l}24,700-44,700 € \\
\text { per life year }\end{array}$ \\
\hline Canada & $\begin{array}{l}\text { CAN\$20,000-100,000 } \\
\text { per QALY }\end{array}$ & $\begin{array}{l}12,700-63,300 € \\
\text { per QALY }\end{array}$ \\
\hline $\begin{array}{l}\text { England } \\
\text { and Wales }\end{array}$ & $\begin{array}{l}£ 20,000-30,000 \\
\text { per OALY }\end{array}$ & $\begin{array}{l}22,800-34,100 € \\
\text { per QALY }\end{array}$ \\
\hline Netherlands & $\begin{array}{l}20,000-80,000 € \\
\text { per OALY }\end{array}$ & $\begin{array}{l}20,000-80,000 € \\
\text { per QALY }\end{array}$ \\
\hline New Zealand & $\begin{array}{l}\text { NZ3,000-15,000 } \\
\text { per QALY }\end{array}$ & $\begin{array}{l}1,400-7,200 € \\
\text { per QALY }\end{array}$ \\
\hline Scotland & $\begin{array}{l}£ 20,000-30,000 \\
\text { per OALY }\end{array}$ & $\begin{array}{l}22,800-34,100 € \\
\text { per QALY }\end{array}$ \\
\hline United States & $\begin{array}{l}\text { US\$50,000 } \\
\text { per QALY }\end{array}$ & $\begin{array}{l}34,400 € \\
\text { per QALY }\end{array}$ \\
\hline
\end{tabular}

Local threshold values were converted into Euro using market exchange rates on 14th September 2009.

ICER, incremental cost-effectiveness ratio; $Q A L Y$, quality-adjusted life year.
The Belgian Medicine Reimbursement Committee does not use a threshold ICER when assessing the value of medicines (Cleemput and Van, 2009). A retrospective analysis reviewed 824 pharmaceutical reimbursement dossiers submitted between 2002 and 2004. Of those dossiers, 81\% gained reimbursement, whereas 19\% did not. If the applicant proved added therapeutic value versus available alternatives, the probability of reimbursement increased to $91 \%$ (Van Wilder and Dupont, 2008).

In Canada, guidelines have been proposed about how valuable a new medicine has to be to warrant utilization (Laupacis et al., 1992). Three grades of recommendation were suggested: the evidence for adoption is strong if a medicine costs less than CAN\$20,000 per QALY; moderate if a medicine costs between CAN\$20,000 per QALY and CAN\$100,000 per QALY; and weak if a medicine costs more than CAN\$100,000 per QALY. The authors acknowledged that these threshold values were arbitrary, but they were chosen following a review of economic evaluations and previously suggested guidelines. It was argued that medicines with an ICER below CAN\$20,000 per QALY are almost universally accepted and are considered to represent an appropriate use of scarce resources. Also, many medicines with an ICER between CAN\$20,000 per QALY and CAN\$100,000 per QALY are provided routinely, although the availability of some medicines is limited and the appropriateness of others for specific patient groups is questioned.

The National Institute for Health and Clinical Excellence (NICE) in England and Wales uses a threshold ICER of $£ 20,000$ per QALY, although health technologies with an ICER above this threshold can be recommended for use in the National Health Service (NHS) if there is a strong case to do so. A review of NICE guidance issued between 1999 and 2005 concluded that health technologies having

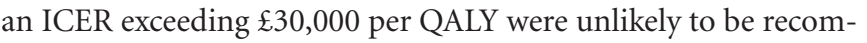
mended (Raftery, 2006). Judgments about what is regarded as an (un)acceptable ICER are made by NICE's advisory committees, which consist of clinicians and health managers working in the NHS, statisticians, health economists, and patients (Rawlins and Culyer, 2004).

In Ireland, there is no threshold ICER value (Tilson and Barry, 2010). In the past, new medicines with an ICER below 45,000 $€$ per QALY tended to be reimbursed. If a medicine has an ICER that is significantly higher than other technologies that have been funded or reimbursed, other factors need to be considered, such as: the level of uncertainty associated with the effectiveness and cost-effectiveness data, the budget impact and the opportunity cost of investing in the new medicine, the innovative nature of the medicine, and the availability of alternatives.

In the late 1990s, a threshold ICER of 20,000 $€$ per QALY has been proposed by the Dutch Health Care Insurance Board (Health Care Insurance Board, 1999). More recently, the Health Council suggested a value of $80,000 €$ per QALY for illnesses associated with a considerable burden. This value reflected the application of the World Health Organization (WHO) threshold ICER to the Netherlands (cfr. infra), a comparison of threshold ICERs used in other countries, and the cost of 1 year of nursing care.

The Pharmaceutical Medicines Agency (PHARMAC) of New Zealand does not use a threshold ICER below which a medicine is considered to provide good value. This is because the size of the budget varies from year to year and because decisions take 
into account criteria other than value. A retrospective analysis of PHARMAC decisions indicates that the threshold ICER was NZ\$11,797 per QALY in 1998/1999; NZ\$3,276 per QALY in 1999/2000; NZ\$13,105 per QALY in 2000/2001; NZ\$2,991 per QALY in 2001/2002; NZ\$8,135 per QALY in 2002/2003; NZ\$15,768 per QALY in 2003/2004; and NZ\$12,117 per QALY in 2004/2005. The cumulative volume-weighted average threshold ICER was NZ\$6,865 per QALY between 1998 and 2005 (PHARMAC, 2007).

The Scottish Medicine Consortium has assessed the value of around 600 medicines from 2002 to 2008 (Webb, 2009). Of these 600 medicines, 30\% were accepted for use, 33\% were accepted for restricted use and $37 \%$ were not recommended. If the cost per

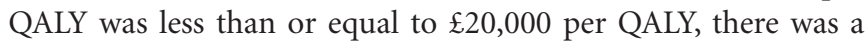
probability of $80 \%$ that the medicine was accepted. If the cost per QALY ranged from $\mathfrak{E} 20,000$ to $\mathfrak{E} 30,000$ per QALY, this probability decreased to $42 \%$. A submission was more likely to succeed if one or more of the following conditions was satisfied: innovative treatment, clear effect on relevant clinical outcomes, sizeable QALY benefit and clear cost per QALY case, direct comparison with current practice, transparent modeling with sensitivity analysis, and data relevant to Scottish patients.

Since the mid-1990s, economic evaluations in the United States commonly apply a threshold ICER of US\$50,000 per QALY (Owens, 1998; Grosse, 2008). Historically, this threshold has been attributed to an economic evaluation examining the value of renal dialysis in end-stage renal disease in 1984. As renal dialysis is the only treatment that Medicare is required to fund, it is argued that US\$50,000 per QALY is an acceptable price to pay for health improvement in the US population. However, since Medicare does not fund other health technologies for all US citizens, it is unknown whether the value of US\$50,000 per QALY actually represents Medicare's threshold ICER. Furthermore, some authors have stated that this value is not based on economic theory, is not derived from expert consensus, and is of questionable empirical validity (Garber and Phelps, 1997; Gafni and Birch, 2006).

\section{THRESHOLD ICERS BASED ON THE VALUE OF A LIFE}

A threshold ICER can be derived from the literature estimating the value of a life. This literature yields an estimate of the value of a QALY (and, thus, the threshold ICER) by applying such techniques as human capital, revealed preference and willingness to pay (Brazier et al., 2007). The human capital approach equates the value of a QALY with the economic productivity of a healthy individual during 1 year. The revealed preference approach infers the value of a QALY from observing individuals' actual behavior in real-life situations that involve willingness to pay to reduce a risk or willingness to accept money to face a risk. For instance, wage-risk studies examine the relationship between the risks associated with a hazardous job and the wage that individuals require to accept such a job, thereby providing information about the value of a QALY. The third technique presents individuals with a hypothetical scenario to elicit their willingness to pay for a particular health improvement.

A review extracted estimates of the value of a life from the literature and used these estimates to calculate the implied value of a QALY (Hirth et al., 2000). Estimates of the value of a life were elicited using the human capital approach (six studies), the revealed preference approach (19 studies on occupational safety and eight studies on non-occupational safety), and the willingness-to-pay approach (eight studies). The median value of a QALY (or the threshold ICER) amounted to US $\$ 24,777$ based on the human capital approach; US\$93,402 based on the approach to reveal preferences about non-occupational safety; US $\$ 428,286$ based on the approach to reveal preferences about occupational safety; and US $\$ 161,305$ based on the willingness-to-pay approach.

Threshold ICERs based on the value of a life suffer from a number of limitations. Typically, the human capital and willingness-to-pay approaches assign a higher weight to the lives of wealthy individuals. Also, it is not always clear whether individuals take into account the impact of a health state on productivity, taxes and income when assessing the value of a QALY. Furthermore, it seems appropriate to found medicine pricing/reimbursement decisions on the notion of societal value. However, the value-of-life literature elicits individual value rather than societal value. A more detailed discussion of the strengths and limitations of the human capital, revealed preference and willingness-to-pay approaches is beyond the scope of this article, but can be found in the specialized literature (Johannesson and Jonsson, 1991; Bayoumi, 2004; Mason et al., 2008).

\section{THRESHOLD ICERS LINKED TO GDP}

The WHO has attempted to provide a more objective national threshold ICER that reflects affordability by tying it to the GDP of a country (WHO Commission on Macroeconomics and Health, 2001). The threshold ICER is expressed in terms of the outcome measure of disability-adjusted life years (DALYs). The DALY gauges disease burden by quantifying the impact of premature death and disability on a population in a single measure. The WHO Commission on Macroeconomics and Health suggested that health technologies costing less than three times GDP per capita for each DALY averted represent good value. The commission justified this threshold ICER on the basis of expected direct and indirect benefits to national economies. This recommendation primarily targeted low-income countries, but can also be applied with(out) adjustment to more affluent countries.

An alternative approach is founded on the notion that each individual is entitled to the per capita GDP as this represents a fair share of a country's wealth (Williams, 2004). An individual could then spend this per capita GDP on improving his/her health during 1 year. In other words, the per capita GDP serves as the threshold value for the average cost-effectiveness ratio. However, as this approach is founded on the average rather than the ICER, it cannot serve as an appropriate value for the threshold ICER. Also, this approach is unrealistic in assuming that a country is willing to allocate its whole GDP to health care. Such an approach could be applied to setting a threshold value for any good or service in the economy and, thus, cannot be used for choosing between any of them (McCabe et al., 2008).

\section{VARIABLE THRESHOLD ICERs AND WEIGHTED ICERS}

The specification of a fixed threshold ICER does not take into account that decision makers may wish to account for other criteria in addition to value when assessing a medicine pricing/reimbursement decision. Other criteria may relate to, for instance, equity considerations. Therefore, decision makers may not wish to apply 
a fixed threshold ICER, but vary the threshold ICER according to the type of medicine, the type of disease, and the decisionmaking context.

This may be the case for orphan medicines, i.e., medicines intended for the diagnosis, prevention or treatment of a lifethreatening or chronically debilitating condition affecting not more than 5 in 10,000 individuals (European Commission, 2000). Given their high price for an often modest effectiveness, orphan medicines are unlikely to provide value if their cost-effectiveness ratio is compared to a fixed threshold value. However, other societal considerations may matter when evaluating an orphan medicine, such as the fact that these medicines tend to target lifethreatening rare diseases for which there is no alternative therapy, and that these medicines have a considerable impact on patients' health care expenditures if they would have to incur the medicine costs themselves. The question arises as to how these various considerations can be aggregated. In other words, how can the often high cost-effectiveness ratio, weak clinical data, small health benefit, high cost and absence of an alternative therapy for orphan medicines be taken into account in a health care payer's decision to cover such a medicine (Denis et al., 2009)? It has been argued that the value of the threshold ICER should be higher for medicines to which society attaches a high social value (Drummond et al., 2009). Orphan medicines may attract a high social value, although future research needs to elicit social values ascribed to various medicines and health technologies.

Another example is oncology medicines. For instance, the Scottish Medicine Consortium has assessed the value of 39 cancer medicines from 2002 to 2005 (Timoney et al., 2006). Of these medicines, 11 medicines were accepted, 15 medicines were accepted with restrictions, and 13 medicines were not recommended. A review of all medicine applications showed that fewer randomized controlled trials were available for oncology medicines and that oncology trials had a longer follow-up period than other medicines. There was evidence that a higher threshold ICER may apply to oncology medicines: although oncology medicines had a higher cost per QALY than other medicines [median of $\mathfrak{1 5}, 000$ (around US\$24,309) per QALY versus $\mathfrak{E} 8,500$ (around US\$13,775) per QALY], acceptance rates were similar (66.7\% versus $66.4 \%$ ).

The use of the ICER to maximize health subject to a budget assumes that "a QALY is a QALY is a QALY" (Weinstein, 1988), irrespective of who receives those QALYs and how they are distributed within society. However, this is not the case in practice: a literature review has demonstrated that the value of a QALY may depend on the amount, duration and type of outcome; the type of individual receiving the QALY (e.g., adolescent versus elderly individuals, individuals suffering from a common versus rare disease, individuals suffering from a less severe versus a more severe disease; individuals with versus without dependents); and the level of health inequality within society (Dolan et al., 2005). Therefore, an alternative approach to specifying variable threshold ICERs is to keep a fixed threshold ICER, but to explicitly take into account such equity considerations by calculating a weighted QALY and, thus, a weighted ICER of a medicine.

For instance, in January 2009, NICE issued methodological guidance on assessing the value of end-of-life medicines and health technologies (National Institute for Health and Clinical
Excellence, 2009). The question was raised whether society would attach the same importance to technologies that extend the life of patients with a short life expectancy and that are licensed for indications affecting a small number of patients with terminal diseases than to other technologies. Based on research that society may assign greater value to, for instance, severe diseases or pediatric diseases, NICE recommended to attach greater weight to QALYs accrued in the later stages of terminal diseases. These weights should consider the uncertainty surrounding the evidence of the medicine's clinical effectiveness and the value which patients with a short life expectancy place on additional months of life.

\section{ALTERNATIVE APPROACHES TO ASSESSING THE VALUE OF MEDICINES}

In light of the strengths and weaknesses of the threshold ICER approach (cfr. supra), a number of alternative approaches have been developed to assess the value of a medicine. This section describes these approaches by focusing on the replacement approach, program budgeting and marginal analysis, the generalized optimization framework, and multi-criteria decision analysis.

\section{REPLACEMENT APPROACH}

In order to assess the value of a new medicine $A$, the replacement approach identifies an existing medicine B which, if cancelled, would generate at least enough resources to fund the incremental costs of medicine A (Sendi et al., 2002). If the incremental outcomes associated with medicine A exceed the outcomes foregone from canceling medicine $\mathrm{B}$, then the health care payer can replace B with A, thereby increasing total health at the same or lower cost. For medicine A to be selected, the replacement approach identifies a medicine $B$ such that:

$\Delta C(A) \leq \Delta C(B)$ and $\Delta E(A) \geq \Delta E(B)$

where $\Delta C(A)$ is the incremental costs of medicine $A ; \Delta C(B)$ is the incremental savings from canceling medicine $B ; \Delta E(A)$ is the incremental outcomes of medicine $A ; \Delta E(B)$ is the incremental outcomes foregone by canceling medicine $\mathrm{B}$.

The advantages of the replacement approach are that the assumptions underlying the threshold ICER approach are not required for this decision rule. However, this approach assumes that it is possible to identify a medicine B so that the resources freed up from canceling $\mathrm{B}$ equal or exceed the additional costs of medicine A. Also, decision makers may find it difficult to discontinue paying for the medicine $\mathrm{B}$ that is replaced by the medicine $\mathrm{A}$. Furthermore, the medicine B may not be the highest value alternative. This approach enhances resource allocation decisions, but does not necessarily maximize population health subject to a budget constraint. Therefore, the replacement approach is a second-best solution for assessing the value of medicines.

\section{PROGRAM BUDGETING AND MARGINAL ANALYSIS}

Program budgeting and marginal analysis is similar to the replacement approach. An expert panel is formed which may consist of such stakeholders as physicians, administrators, patients etc. Within the constraints of a program budget, this panel needs to identify programs for service expansion, the costs of which 
are paid by reducing other programs. If this process increases population health, resources are switched from current programs to programs identified for service expansion (Mitton and Donaldson, 2003).

This approach determines which programs need to be expanded or reduced by means of the ICER of each program (Mitton and Donaldson, 2004). Therefore, program budgeting and marginal analysis has similar strengths and weaknesses of the threshold ICER approach. In practice, only France has delisted programs in recent years (Sermet et al., 2010).

\section{GENERALIZED OPTIMIZATION FRAMEWORK}

Decision makers need to allocate resources to indivisible medicines associated with non-constant returns to scale and need to take into account political, administrative, technical, and ethical constraints. A generalized optimization framework using mathematical programming techniques has been proposed to maximize population health subject to a budget and other constraints (Birch and Gafni, 2006a). However, such an approach requires data on the available budget, costs and outcomes of all medicines and comparators. In practice, such data are not available in most health care systems, thus inhibiting the practical applicability of the generalized optimization framework.

\section{MULTI-CRITERIA DECISION ANALYSIS}

Decision makers are likely to consider other criteria in addition to value. For instance, decision makers may wish to maximize population health subject to a budget, to reduce health inequalities in the population, to prioritize preventive over curative care, and to attach more importance to life-threatening rare diseases.

According to multi-criteria decision analysis, an expert panel defines the relevant decision-making criteria and their relative importance. Each criterion needs to be measurable, so that the degree to which a medicine attains the criterion can be assessed.
Different techniques to aggregate the scores of a medicine on the different criteria can be applied to calculate the overall performance of a medicine. It follows that decision makers allocate resources based on the ranking of medicines according to their performance scores until the budget is exhausted (Baltussen and Niessen, 2006).

\section{THE VALUE OF GENERIC MEDICINES}

The previous sections have presented approaches to assessing the value of originator medicines that are protected by patents. Once the patent expires, generic medicines can enter the market. A generic medicine is a medicinal product which has the same qualitative and quantitative composition in active substances and the same pharmaceutical form as the reference medicinal product, and whose bio-equivalence with the reference medicinal product has been demonstrated by appropriate bio-availability studies (European Commission, 2004).

Generic medicines provide value as they provide the same effectiveness as the originator medicine, but at a lower cost. Generic medicines tend to be cheaper than originator medicines because generic medicines companies incur lower cost of research and development than originator medicines companies and because many countries regulate prices of generic medicines that wish to benefit from reimbursement. Competition from generic medicines may also incite originator companies to reduce prices on off-patent originator medicines, thus generating additional savings to health care payers and patients.

National generic medicines markets have developed over the last decade with a view to curbing pharmaceutical expenditure without impeding the provision of health care. However, Figure 2 shows that the size of generic medicines markets varies (European Generic Medicines Association, 2008). Variation in the development of generic medicines markets owes, amongst other things, to differences in the policy and regulatory environment surrounding

\section{Generic Market Shares 2007 Total Market (Volume)}

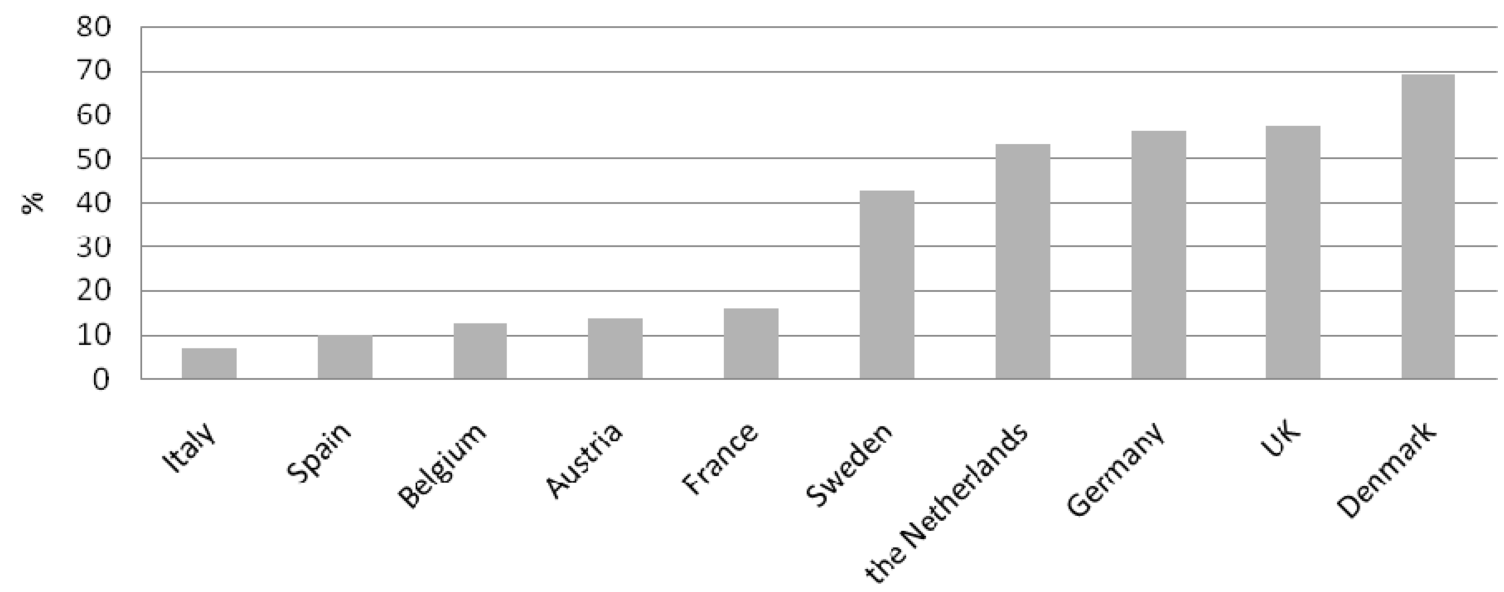

FIGURE 2 | Generic market shares by volume of total medicines market in 2007. 
generic medicines. This variation suggests that not all countries are realizing their full potential in generic medicines. For instance, an analysis indicated that increased generic substitution for the top 10 active substances in 11 European countries in 2004 would generate total potential savings of around 3 billion $€$ (Simoens and De Coster, 2006).

\section{CONCLUSIONS}

The basic principle underlying economic evaluation of medicines is that the ICER provides information that can be used to maximize health subject to a budget constraint. Health is maximized by selecting medicines with increasing ICERs until the budget is exhausted. This method is generally applicable and has been used in decision making surrounding reimbursement of medicines in many countries. The value of the threshold ICER should reflect societal preferences. This also implies that decision makers may

\section{REFERENCES}

European Commission.(2000). Regulation (EC) No 141/2000 of the European Parliament and the Council of 16 December 1999 on orphan medicinal products. Official Journal of the European Communities L 18/1.

Baltussen, R., and Niessen, L. (2006). Priority setting of health interventions: the need for multi-criteria decision analysis. Cost. Eff. Resour. Alloc. 4, 14.

Barrett, A., Roques, T., Small, M., and Smith, R. D. (2006). How much will Herceptin really cost? BMJ 333 , 1118-1120.

Bayoumi,A.M.(2004). The measurement of contingent valuation for health economics. Pharmacoeconomics 22, 691-700.

Bell, C. M., Urbach, D. R., Ray, J. G., Bayoumi, A., Rosen, A. B., Greenberg, D., and Neumann, P. J. (2006). Bias in published cost effectiveness studies: systematic review. BMJ 332, 699-703.

Birch, S., and Gafni, A. (2006a). "Decision rules in economic evaluation," in The Elgar Companion to Health Economics, ed. A. Jones (Northampton: Edward Elgar), 492-502.

Birch, S., and Gafni, A. (2006b). Information created to evade reality (ICER): things we should not look to for answers. Pharmacoeconomics 24, 1121-1131.

Brazier, J., Ratcliffe, J., and Salomon, J. (2007). Measuring and Valuing Health Benefits for Economic Evaluation. Oxford: Oxford University Press.

Cleemput, I., and Van, W. P. (2009). History of health technology assessment in Belgium. Int. J. Technol. Assess. Health Care 25(Suppl. 1), 82-87.

Cohen, J., Stolk, E., and Niezen, M. (2007). The increasingly complex fourth hurdle for pharmaceuticals. Pharmacoeconomics 25, 727-734.

Denis, A., Simoens, S., Fostier, C., Mergaert, L., and Cleemput, I. (2009). Health technology assessment of policy governing orphan diseases and orphan drugs Brussels.

Dolan, P., Shaw, R., Tsuchiya, A., and Williams, A. (2005). QALY maximisation and people's preferences: a methodological review of the literature. Health Econ. 14, 197-208.

Donaldson, C., and Gerard, K. (2005). Economics of Health Care Financing: The Visible Hand. Basingstoke: Palgrave Macmillan.

Drummond, M., Evans, B., LeLorier, J., Karakiewicz, P., Martin, D., Tugwell, P., and MacLeod, S. (2009). Evidence and values: requirements for public reimbursement of drugs for rare diseases - a case study in oncology. Can. J. Clin. Pharmacol. 16, e273-e281.

Drummond, M., Sculpher, M. J., Torrance, G. W., O’Brien, B. J., and Stoddart, G. L. (2005). Methods for the Economic Evaluation of Health Care Programmes. Oxford: Oxford

Eichler, H. G., Kong, S. X., Gerth, W. C., Mavros, P., and Jonsson, B. (2004). Use of cost-effectiveness analysis in healthcare resource allocation decisionmaking: how are cost-effectiveness thresholds expected to emerge? Value Health 7, 518-528.

European Commission. (2004). Directive 2004/27/EC of the European Parliament and of the Council of 31st March 2004 amending Directive 2001/83/EC on the Community code relating to medicinal products for human use. Official J. Eur. Union L136, 34-57.

European Generic Medicines Association. (2008). EGA Market Review (2007) University Press.

wish to vary the threshold ICER according to the type of medicine, the type of disease, and the decision-making context. For instance, a higher threshold value may be applied to orphan medicines or to oncology medicines.

Other approaches to assessing the value of medicines (e.g., the replacement approach and program budgeting and marginal analysis) have focused on improving resource allocation rather than maximizing health subject to a budget constraint, and therefore are not recommended. Instead, decision makers can draw on the generalized optimization framework and multi-criteria decision analysis, when they wish to consider multiple criteria when assessing the value of a medicine.

\section{ACKNOWLEDGMENT}

Financial support for this research project was received from Pharma.be.

Brussels: European Generic Medicines Association.

Gafni,A., and Birch, S. (2006). Incremental cost-effectiveness ratios (ICERs): the silence of the lambda. Soc. Sci. Med. 62, 2091-2100.

Garber, A., and Phelps, C. (1997) Economic foundations of cost-effectiveness analysis. J. Health Econ. $16,1-31$.

George, B., Harris, A., and Mitchell, A. (2001). Cost-effectiveness analysis and the consistency of decision making: evidence from pharmaceutical reimbursement in australia (1991 to 1996). Pharmacoeconomics 19, 1103-1109.

Godman, B., Wettermark, B., Hoffmann, M., Andersson, K., Haycox, A., and Gustafsson, L. L. (2009). Multifaceted national and regional drug reforms and initiatives in ambulatory care in Sweden: global relevance. Expert Rev. Pharmacoecon. Outcomes Res. 9, 65-83.

Grosse, S. D. (2008). Assessing cost-effectiveness in healthcare: history of the $\$ 50,000$ per QALY threshold. Expert Rev. Pharmacoecon. Outcomes Res. 8 , 165-178.

Health Care Insurance Board. (1999). Richtlijnen Voor Farmaco-Economisch Onderzoek (Guidelines for PharmacoEconomic Research). Amstelveen: Health Care Insurance Board.

Hirth, R. A., Chernew, M. E., Miller, E., Fendrick, A. M., and Weissert, W. G. (2000). Willingness to pay for a quality-adjusted life year: in search of a standard. Med. Decis. Making 20, 332-342.

Johannesson, M., and Jonsson, B. (1991) Economic evaluation in health care: is there a role for cost-benefit analysis? Health Policy 17, 1-23.

Laupacis, A., Feeny, D., Detsky, A. S., and Tugwell, P. X. (1992). How attractive does a new technology have to be to warrant adoption and utilization? Tentative guidelines for using clinical and economic evaluations. CMAJ 146 , 473-481.

Mason, H., Baker, R., and Donaldson, C. (2008). Willingness to pay for a QALY: past, present and future. Expert Rev. Pharmacoecon. Outcomes Res. 8, 575-582.

McCabe, C., Claxton, K., and Culyer, A. J. (2008). The NICE cost-effectiveness threshold: what it is and what that means. Pharmacoeconomics 26, 733-744.

Mitton, C., and Donaldson, C. (2004). Priority Setting Toolkit: A Guide to the Use of Economics in Healthcare Decision-Making. London: BMJ Books.

Mitton, C. R., and Donaldson, C. (2003). Setting priorities and allocating resources in health regions: lessons from a project evaluating program budgeting and marginal analysis (PBMA). Health Policy (New York) 64, 335-348.

National Institute for Health and Clinical Excellence. (2009). Appraising LifeExtending, End of Life Treatments. London: National Institute for Health and Clinical Excellence.

Owens, D. K. (1998). Interpretation of cost-effectiveness analyses. J. Gen. Intern. Med. 13, 716-717.

PHARMAC. (2007). Prescription for Pharmacoeconomic Analysis: Methods for Cost-Utility Analysis. Auckland: PHARMAC.

Raftery, J. (2006). Review of NICE's recommendations, 1999-2005. BMJ332, 1266-1268.

Rawlins, M. D., and Culyer, A. J. (2004). National Institute for Clinical Excellence and its value judgments. BMJ 329, 224-227. 
Sendi, P., Gafni, A., and Birch, S. (2002). Opportunity costs and uncertainty in the economic evaluation of health care interventions. Health Econ. 11, 23-31.

Sermet, C., Andrieu, V., Godman, B., Van, G. E., Haycox, A., and Reynier, J. P. (2010). Ongoing pharmaceutical reforms in France: implications for key stakeholder groups. Appl. Health Econ. Health Policy 8, 7-24.

Simoens, S., and De Coster, S. (2006). Potential savings from increased substitution of generic for originator medicines in Europe. J. Generic Med. 4, 43-45.

Stinnett, A. A., and Mullahy, J. (1998). Net health benefits: a new framework for the analysis of uncertainty in costeffectiveness analysis. Med. Decis. Making 18, S68-S80.

Tilson, L., and Barry, M. (2010). Recent developments in pharmacoeconomic evaluation in Ireland. Expert Rev. Pharmacoecon. Outcomes Res. 10, 221-224.

Timoney,A.,Walker,A.,Paterson,K.,Bennie, M., McIver, L., and Webb, D. (2006). The Scottish Medicine Consortium - Are Oncology Medicines Different? Adelaide: Third Health Technology Assessment International Conference.

Van Wilder, P., and Dupont, A. (2008). Introducing evidence-based medicine in reimbursement procedures: does it affect the outcome? Value Health 11, 784-787.

Webb, D. (2009). Early Assessment of CostEffectiveness, 14-7-2009. Edinburgh: Congress of the European Association for Clinical Pharmacology and Therapeutics.

Weinstein, M. C. (1988). A QALY is a QALY - or is it? J. Health Econ. 7, 289-290.
Weinstein, M. C., and Zeckhauser, R. (1973). Critical ratios and efficient allocation. J. Public Econ. 2, 147-157.

Wettermark, B., Godman, B., Andersson, K., Gustafsson, L. L., Haycox, A., and Bertele, V. (2008). Recent national and regional drug reforms in Sweden: implications for pharmaceutical companies in Europe. Pharmacoeconomics $26,537-550$.

WHO Commission on Macroeconomics and Health. (2001). Macroeconomics and Health: Investing in Health for Economic Development. Geneva: World Health Organisation.

Williams, A. (2004). What Could be Nicer than NICE? London: Office of Health Economics.

Conflict of Interest Statement: The author declares that the research was con- ducted in the absence of any commercial or financial relationships that could be construed as a potential conflict of interest.

Received: 17 June 2010; paperpending published: 07 July 2010; accepted: 11 August 2010; published online: 07 September 2010. Citation: Simoens S (2010) How to assess the value of medicines? Front. Pharmacol. 1:115. doi: 10.3389/fphar.2010.00115

This article was submitted to Frontiers in Pharmaceutical Medicine and Outcomes Research, a specialty of Frontiers in Pharmacology.

Copyright (ㅇ 2010 Simoens. This is an open-access article subject to an exclusive license agreement between the authors and the Frontiers Research Foundation, which permits unrestricted use, distribution, and reproduction in any medium, provided the original authors and source are credited. 